\title{
Gastric Cardia Intestinal Metaplasia: Biopsy Follow-Up of 85 Patients
}

Neal S. Goldstein, M.D.

Department of Anatomic Pathology, William Beaumont Hospital, Royal Oak, Michigan

Background: Gastric cardia intestinal metaplasia (CIM), denoted by goblet cells is common. The frequency of persistent CIM is unknown. Methods: 85 patients with CIM and follow-up endoscopies were prospectively identified during the time period of 10/6/94-12/21/97. The presence of goblet cells was the defining feature of CIM, other metaplastic cell types were not evaluated. All 85 patients initially had biopsies that straddled the squamocolumnar junction (SCJ) showed CIM, an otherwise normal proximal stomach, lower esophagus, and squamocolumnar junction. The SCJ lay within the $2 \mathrm{~cm}$ of mucosa immediately proximal to the uppermost gastric fold and overlaid the junction of the tubular esophagus and the saccular dilatation of the stomach in all patients. The patients underwent endoscopy for many reasons. They were randomly identified based on the absence of a hiatal hernia and the presence of CIM. Results: Ten of the 85 patients had CIM on repeat biopsy. Among patients with no CIM in the first repeat endoscopy, the degree of cardia inflammation decreased between the initial and first repeat endoscopy, whereas there was no change in the amount of inflammation among patients who had CIM in the first repeat endoscopy. The changes in mean inflammation score was significantly different between the two groups $(P=$ .024). Twenty-two patients underwent a second repeat endoscopy and five had a third repeat endoscopy. Including all follow-up biopsies, six of the 85 patients (7\%) had CIM. Four patients who did not have CIM on initial repeat endoscopy had CIM on their second repeat endoscopy, probably reflecting sampling issues. None of the biopsies had dysplasia. Conclusions: Cardia inflammation is a stimulus for cardia intestinal metaplasia, and a reduction in in-

Copyright () 2000 by The United States and Canadian Academy of Pathology, Inc.

VOL. 13, NO. 10, P. 1072, 2000 Printed in the U.S.A.

Date of acceptance: May 11, 2000.

Address reprint requests to: Neal Goldstein, M.D., Department of Anatomic Pathology, William Beaumont Hospital, 3601 West Thirteen Mile Road, Royal Oak, MI 48073; e-mail: ngoldstein@beaumont.edu; fax: 248551-9054. flammation may allow the metaplastic mucosa to revert to normal.

KEY WORDS: Barrett's esophagus, Cardia, Dysplasia, Esophagus, Inflammation, Intestinal metaplasia.

Mod Pathol 2000;13(10):1072-1079

Gastric cardia intestinal metaplasia (CIM), defined as goblet cells within cardia mucosa, is a recently described pathologic process that occurs in 6 to $57 \%$ of patients with normal squamocolumnar junction regions (1-24). Although the columnar epithelium of Barrett's esophagus is thought not to significantly regress, it is unknown whether CIM represents a permanent or reversible metaplasia. Cardia intestinal metaplasia may have the potential to undergo metaplasia back to its original nonintestinalized epithelium.

This study examines histology of follow-up cardia biopsies of 85 patients who had CIM on initial endoscopy to address these questions.

\section{MATERIALS AND METHODS}

Eighty-five patients with normal gastroesophageal anatomy and a gastric cardia biopsy that contained intestinal metaplasia, defined as the presence of goblet cells, were prospectively identified during the time period of October 6, 1994 to December 21, 1997 from the file of the William Beaumont Hospital Surgical Pathology Department. Only goblet cells were evaluated; no other metaplastic cell types that have been described in Barrett's esophagus were studied. All patients underwent upper endoscopy for upper gastrointestinal symptoms, had endoscopically normal gastroesophageal anatomy, and had biopsies of the antrum, cardia, and lower esophageal squamous mucosa. All patients came from the practices of eight gastroenterologists. Patients who had prior gastric or esophageal surgery were excluded.

The anatomy of the proximal stomach and lower esophagus was extracted from endoscopy reports and discussions with gastroenterologists, who, if 
necessary, reviewed the endoscopic photographs of the gastroesophageal junction. Definitions of normal gastroesophageal anatomy were strictly and rigidly applied. All patients included in the study initially had a normal proximal stomach, lower esophagus, and squamocolumnar junction (Z-line). The squamocolumnar junction lay within the $2 \mathrm{~cm}$ of mucosa immediately proximal to the uppermost (proximal) gastric fold and overlaid the junction of the tubular end of the esophagus and the saccular dilatation of the stomach. No patients had a prominent or exaggerated squamocolumnar junction in which a columnar mucosa tongue greater than 1 or $2 \mathrm{~mm}$ extended into the lower esophagus. The patients underwent endoscopy for many reasons, and were randomly identified based on the absence of a hiatal hernia and the presence of CIM. Inclusion in the study required at least one repeat endoscopy. Patients were also excluded from the study if the presence or absence of specific anatomic features and relationships were not mentioned in the procedure notes or were not clear from the retroflexedpositioned photographs. In order to maintain a cautious and conservative approach to patient inclusion in the study, patients were excluded if there was possibility that a short tongue of columnar mucosa extended above the junction of the saccular stomach and tubular esophagus for a distance greater than $2 \mathrm{~mm}$. Specific symptom information was not recorded. Excluding the specific descriptions of the gastroesophageal junction, endoscopic appearances in relation to categorizing the nature of any inflammation of the lower esophagus and stomach were not used in the study.

All patients initially had a biopsy that straddled the squamocolumnar junction composed of squamous and columnar mucosa via retroflexed endoscope. Most patients also had an additional pure squamous mucosa biopsy procured from the lower $2 \mathrm{~cm}$ of the esophagus, and a biopsy fragment composed only of columnar mucosa from the cardia region within $1 \mathrm{~cm}$ below the squamocolumnar junction. Tissue was submitted in Hollande's solution. All the blocks were cut in an identical manner. Three levels were cut, with approximately $200 \mu \mathrm{m}$ between each level.

The following histologic features within the cardia mucosa were examined:

\section{Gastric cardia inflammation}

Classifications were noted as mild, moderate, or marked using the written criteria and color drawings of the visual analogue scales provided within the updated Sydney Gastritis Classification system (25). For comparison and statistical purposes, mild inflammation was given a value of 1 , moderate inflammation was given a value of 2 , and marked inflammation was given a value of 3 .

\section{Amount of gastric cardia intestinal metaplasia}

Intestinal metaplasia was defined as the presence of goblet cells. All biopsies had Alcian blue, $\mathrm{pH} 2.5$ stains to confirm the presence of goblet cells. The amount of intestinal metaplasia was classified as focal (goblet cells within one foveola or gland), moderate (goblet cells within 2 to 5 foveola or glands), or extensive (goblet cells within more than 5 glands).

Almost all of the patients initially had tissue procured from esophageal squamous mucosa that accompanied gastric cardia mucosa biopsies in the same container and from the gastric antrum that was placed in a separate specimen container. The amount of esophageal squamous GERD changes, cardia Helicobacter pylori infection, and gastric antrum inflammation and Helicobacter pylori infection was quantified in these biopsies, and are reported in a prior study (26). Too few patients had repeat esophageal squamous or gastric antrum tissue biopsies to allow for meaningful comparisons and analyses. Therefore, this study was restricted to the changes within cardia and SCJ mucosa. Thirtyfive patients (41\%) had Helicobacter pylori identified in their antral biopsies.

All of the biopsies were procured with standard, 2.2-mm (closed) cup, standard biopsy forceps. The initial endoscopic biopsies were randomly reviewed as a single group, and the repeat endoscopic biopsies (from all of the endoscopies) were randomly reviewed as a second group. The histology of the patient's initial endoscopic biopsies was unknown when the repeat endoscopic biopsies were being reviewed. Which of the repeat endoscopies was also unknown when the review of the repeat endoscopic biopsies was being performed.

\section{RESULTS}

\section{Initial Endoscopy}

The median and mean ages at the time of the initial endoscopy were 58 and 55 years, respectively (range, 29 to 74; standard deviation, 10.8 years). Fifty-eight patients (68\%) were male. The median number of cardia tissue fragments examined per patient was two (range, one to four).

All patients, by definition of patient inclusion in the study, had goblet cells in the gastric cardia in the initial biopsy. Fifty-six (66\%) patients had focal gastric cardia goblet cells, 27 (32\%) had moderate goblet cells, and two (2\%) had extensive goblet cells. Cardia intestinal metaplasia was present on one biopsy tissue fragment in all of the cases with focal and moderate numbers of goblet cells. Goblet cells were present on two biopsy tissue fragments in one of the two patients with extensive goblet cells, and on three biopsy tissue fragments in the other. The 
amount of cardia intestinal metaplasia was similar between section levels in all of the cases with moderate or extensive cardia intestinal metaplasia. The amount of cardia intestinal metaplasia was similar between section levels in all of the cases with moderate or extensive cardia intestinal metaplasia. However, it was found on only one of three levels in two biopsies, and two of three levels in one biopsy that had focal intestinal metaplasia.

All of the biopsies had the appearance of incomplete intestinal metaplasia, consisting of gastric foveolar, columnar, and goblet cells. None of the biopsies had complete intestinal metaplasia with columnar absorptive and goblet cells (27-30).

Seven patients $(8 \%)$ had no cardia inflammation, $34(40 \%)$ had mild inflammation, 35 (41\%) had moderate inflammation, and nine (11\%) had marked inflammation (Table 1). The amount of inflammation was similar between the biopsy fragments. The goblet cells were present in the tissue fragment with the greatest amount of inflammation in eight of the nine cases with marked inflammation. There were no appreciable associations between the amount of cardia intestinal metaplasia and the amount of cardia inflammation $(P=.36)$.

\section{First Repeat Endoscopy}

All 85 patients had a repeat endoscopy that was performed at mean and median time periods of 2.07 and 1.98 years after the first endoscopy, respectively (range, 14 weeks to 4.3 years; standard deviation, 0.89 years). The median number of gastric cardia tissue fragments per patient was three (range, one to seven; standard deviation, 1.34). Ten patients had gastric cardia intestinal metaplasia on repeat endoscopy. The median time interval between endoscopies in these 10 patients was 1.13 years (range, 43 weeks to 2.9 years; standard deviation, 0.60 years). Four patients had focal intestinal metaplasia, five had moderate, and one had extensive. Cardia intestinal metaplasia was present in a single biopsy fragment in the four patients with focal and five patients with moderate intestinal metaplasia. Cardia intestinal metaplasia was present in three of six biopsy fragments in the patient with extensive cardia metaplasia. The amount of cardia intestinal metaplasia was similar between section levels in all of the cases with moderate or extensive cardia intestinal metaplasia. The amount of cardia intestinal metaplasia was similar between section levels in all of the cases with moderate or extensive cardia intestinal metaplasia. However, it was found on only one of three levels in one biopsy from the repeat endoscopy biopsies.

Twenty-six patients $(31 \%)$ had no cardia inflammation, 46 (54\%) had mild inflammation, 13 (12\%) had moderate inflammation, and no patients had marked inflammation (Table 1). The amount of cardia inflammation was similar in all of the biopsy fragments from each patient. Cardia intestinal metaplasia was absent in all 26 patients with no cardia inflammation. Four of the $46(9 \%)$ patients with mild inflammation, and six of the 13 (46\%) of the patients with marked cardia inflammation had cardia intestinal metaplasia. The amount of inflammation was similar in the different biopsy fragments in the patients with moderate and mild inflammation. The biopsy tissue fragment(s) with cardia intestinal metaplasia did not contain an appreciably greater amount of inflammation than did those without cardia intestinal metaplasia.

Eight patients had one to three, 1- to 2-mm long tongues of columnar mucosa that possibly extended into the lower esophagus that were not seen on initial endoscopy. The gastroenterologist who performed the initial and repeat endoscopy was the same in all eight patients. On interrogation of the gastroenterologist, these tongues were equivocally abnormal in three patients, and within the spectrum of normal anatomy in five patients. Four of these eight patients had intestinal metaplasia in the gastric cardia biopsies that were procured from these regions. The histology of these biopsies was identical to the initial endoscopic biopsies.

TABLE 1. Cardia Inflammation and Intestinal Metaplasia

\begin{tabular}{|c|c|c|c|c|}
\hline & \multicolumn{4}{|c|}{ Cardia Inflammation } \\
\hline & None & Mild & Moderate & Marked \\
\hline \multicolumn{5}{|l|}{ Initial endoscopy } \\
\hline$N=85$ & 7 & 34 & 35 & 9 \\
\hline Number with intestinal metaplasia & $7(100 \%)$ & $34(100 \%)$ & $35(100 \%)$ & $9(100 \%)$ \\
\hline \multicolumn{5}{|l|}{ First repeat endoscopy } \\
\hline$N=85$ & 26 & 46 & 13 & 0 \\
\hline Number with intestinal metaplasia (\%) & 0 & $4(9 \%)$ & $6(46 \%)$ & 0 \\
\hline \multicolumn{5}{|l|}{ Second repeat endoscopy } \\
\hline$N=22$ & 2 & 19 & 1 & 0 \\
\hline Number with intestinal metaplasia (\%) & $1(50 \%)$ & $6(32 \%)$ & 0 & 0 \\
\hline \multicolumn{5}{|l|}{ Third repeat endoscopy } \\
\hline$N=5$ & 2 & 3 & 0 & 0 \\
\hline Number with intestinal metaplasia (\%) & 0 & $3(100 \%)$ & 0 & 0 \\
\hline
\end{tabular}




\section{Second Repeat Endoscopy}

Twenty-two patients underwent a second repeat endoscopy, including all ten patients with CIM on the first repeat endoscopy. The median time period of this endoscopy after the initial endoscopy was 3.1 years (range, 1.1 to 4.6 years; standard deviation, 0.97 years). The median time period of this endoscopy after the first repeat endoscopy was 1.75 years (range, 0.1 to 3.5 years). The median number of gastric cardia tissue fragments was four (range, one to six; standard deviation, 1.0). Seven of the 22 patients had CIM, three had focal, and four had moderate amounts. One of the two patients with no cardia inflammation had cardia intestinal metaplasia and six of the 19 patients (32\%) with mild inflammation had intestinal metaplasia (Table 1).

All eight patients who had a short tongue of columnar mucosa in the first repeat endoscopy underwent a second repeat endoscopy. The tongues of columnar mucosa were not seen on the second repeat endoscopy in seven patients. No cardia intestinal metaplasia was present in the second repeat endoscopy cardia biopsies in these seven patients. One of these eight patients, who had a short tongue of columnar mucosa in the first repeat endoscopy, had an identical, single broad based, 2-mm tongue of columnar mucosa that possibly extended into the lower esophagus. A second patient, who had a normal cardia with CIM on the previous biopsy also had a single, broad based, 2-mm tongue of columnar mucosa that possibly extended into the lower esophagus. The same gastroenterologist performed all three endoscopies in each patient. The gastroenterologists thought that the columnar tongue in each patient was equivocally abnormal and within the spectrum of normal anatomy. The biopsies from the columnar tongue and cardia were submitted in the same container for each patient and were comprised of noninflamed cardia mucosa without intestinal metaplasia. The final conclusion was that the short, broad based, columnar tongues were part of a prominent, wavy, but normal SCJ.

\section{Third Repeat Endoscopy}

Five patients underwent a third repeat endoscopy, a median of 4.4 years after the initial endoscopy (range, 3.1 to 4.7 years; standard deviation, 0.62 years). The median time interval between this endoscopy and the second repeat endoscopy was 1.45 years (range, 0.8 to 2.0 years). The median number of cardia tissue fragments was four (range, three to five). Three of the five patients had CIM, which was moderate in two and extensive in one. Two patients had no cardia inflammation. Three patients had mild inflammation, all of which had cardia intestinal metaplasia (Table 1). Tongues of columnar mucosa were not seen in the lower esophagus in any of the five patients.

\section{Inflammation and Cardia Intestinal Metaplasia}

The mean amount of cardia inflammation in initial biopsy specimens was similar between patients with and without intestinal metaplasia in first repeat endoscopy cardia biopsies (1.7 and 1.5, respectively) (Table 2). The mean amount of the first repeat endoscopy cardia inflammation was 0.7 in patients with no cardia intestinal metaplasia on first repeat endoscopy biopsies, and 1.6 in patients with cardia intestinal metaplasia. The change in mean inflammation score was significantly different between patients with no intestinal metaplasia in the first repeat endoscopy biopsies and patients with intestinal metaplasia in the first repeat endoscopy cardia biopsies (Jonckhere-Terpstra, threerow test, exact $P$ value $=.024$ ). Comparisons between subsequent endoscopic biopsies were not done because of the small number of patients.

\section{Temporal Relationships of Cardia Intestinal Metaplasia}

Figure 1 shows an overall schematic flow chart of cardia histology from all of the endoscopies. Including all the repeat endoscopic procedures, six of the 85 patients $(7 \%)$ had cardia intestinal metaplasia on biopsies from their final endoscopy which occurred a mean and median of 2.6 and 2.4 years after the initial endoscopy respectively (range, 0.53 to 4.7 years; standard deviation, 1.02 years).

Figure 2 shows the detailed, subsequent biopsy results of the 10 patients with CIM on the initial repeat endoscopy. All 10 patients had a second repeat endoscopy, of which three had CIM. Two of these three patients had a third repeat endoscopy, both of which also had CIM.

Figure 3 shows the detailed, subsequent biopsy results of the 75 patients with no cardia intestinal

TABLE 2. Inflammation Among Patients With and Without Cardia Intestinal Metaplasia on First Repeat Endoscopy

\begin{tabular}{lcc}
\hline & \multicolumn{2}{c}{ Mean Inflammation Score } \\
\cline { 2 - 3 } & $\begin{array}{c}\text { No Intestinal Metaplasia on } \\
\text { First Repeat Endoscopy } \\
\text { First Repeat Endoscopy }\end{array}$ & 1.7 \\
Initial endoscopy & 0.7 & 1.5 \\
First repeat endoscopy & 1.6 \\
\hline
\end{tabular}




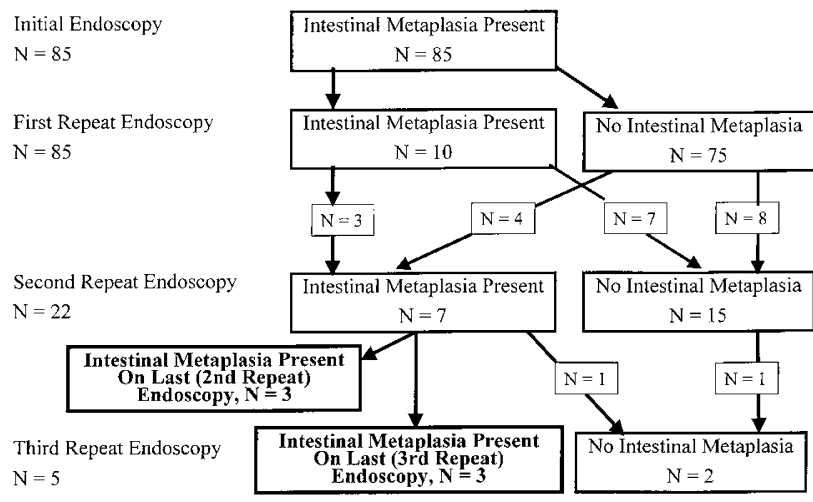

FIGURE 1. Course of cardia intestinal metaplasia (CIM) from initial through repeat endoscopies. Of the 85 patients with CIM on the initial endoscopy, only six had persistent CIM on repeat endoscopy.

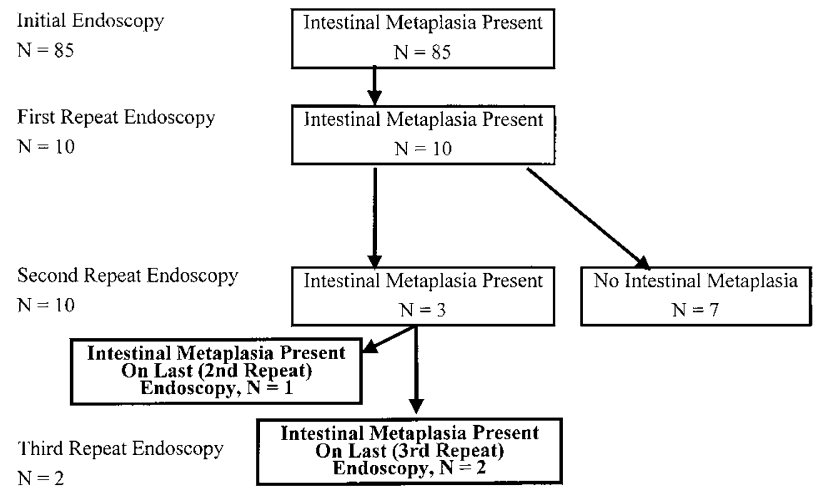

FIGURE 2. Course of the 10 patients with CIM on initial repeat endoscopy. Three of the 10 patients had CIM on second or third repeat endoscopies.

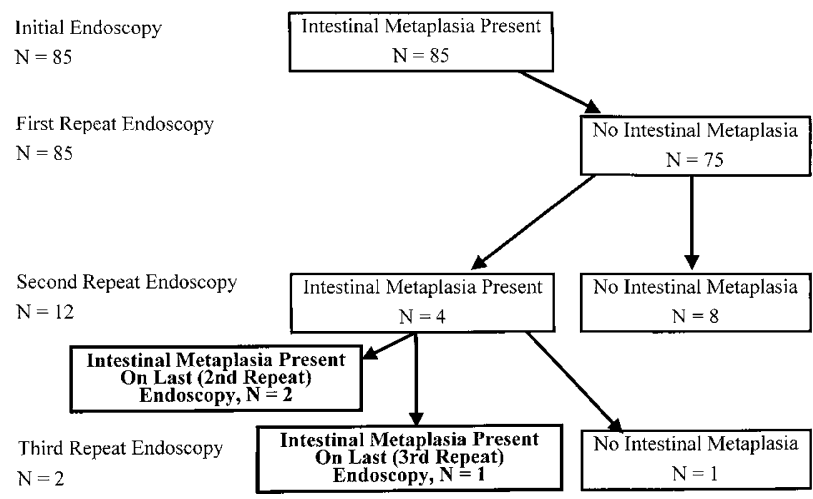

Endoscopy, $\mathrm{N}=1$.

$\mathrm{N}=$

FIGURE 3. Course of the 75 patients without CIM on initial repeat endoscopy. Cardia intestinal metaplasia was present again in four patients on second repeat endoscopy, and absent in one of the two patients who underwent a third repeat endoscopy. These fluctuations may be the result of sampling bias.

metaplasia on the initial repeat endoscopy. Twelve of the 75 patients underwent a second repeat endoscopy. Cardia intestinal metaplasia was present in four of these 12 patients. Of the four patients with cardia intestinal metaplasia on a second repeat endoscopy, two had a third repeat endoscopy, in which one had cardia intestinal metaplasia, and one had no cardia intestinal metaplasia.

\section{Epithelial Dysplasia}

Dysplasia or indefinite for dysplasia epithelial changes were not seen on any of the initial or repeat endoscopy gastric cardia biopsies in the study.

\section{Intraobserver Variation}

All of the initial and first repeat endoscopic biopsies were mixed together, reevaluated in a blinded manner, and scored for the amount of cardia inflammation approximately 12 mo after the last first repeat biopsies were evaluated. The simple and weighted kappa statistics values from the symmetry test comparing the inflammatory scores between the two reviews were 0.59 and 0.61 , respectively. The change in mean cardia inflammation scores between the initial and first repeat endoscopies was compared using the inflammatory scores from the blinded reevaluation of the biopsies. Identical to comparison using the first set of cardia inflammation scores, the mean cardia inflammation score was significantly different between patients with no intestinal metaplasia in the first repeat endoscopy biopsies and patients with intestinal metaplasia in the first repeat endoscopy cardia biopsies (Jonckhere-Terpstra, three-row test, exact $P$ value $=$ .046).

\section{DISCUSSION}

This study found that persistent cardia intestinal metaplasia was present on repeat endoscopy in $7 \%$ of 85 patients who had cardia intestinal metaplasia on initial endoscopy. These results are similar to those of DeMeester et al. (31) who noted the disappearance of CIM after fundoplication surgery in 11 of $15(73 \%)$ patients, but are opposite those of a recent study of 251 patients who were followed for 6 mo after completion of Helicobacter pylori therapy (32). The authors of the latter study reported the highest percentage of patients with CIM in the literature. Forty-four percent of patients had CIM at the start of their study, which increased to $55 \%$ at the six-month endoscopy, despite significant decreases in cardia inflammation. The results of this study are questionable because these authors also reported that $18.7 \%$ of the patients had cardia dysplasia at the start of the study, which decreased to $2.4 \%$ at the six-month endoscopy. Another small study published in abstract form reported persistence of CIM among four patients treated with antiHelicobacter pylori therapy (33).

Cardia intestinal metaplasia in repeat endoscopic biopsies was significantly associated with greater amounts of inflammation compared to biopsies with no intestinal metaplasia. The amount of initial and first repeat cardia inflammation were almost 
identical among those patients with cardia intestinal metaplasia on repeat endoscopy. However, CIM was absent in all of the patients with no cardia inflammation on repeat endoscopic biopsies. In those without CIM who continued to have cardia inflammation on the repeat biopsy, cardia inflammation was significantly less than that in the initial cardia biopsy in which cardia intestinal metaplasia was present. Cardia intestinal metaplasia has been related to the amount of cardia inflammation in other studies $(5,22,26)$. Taken together, these results suggest that cardia inflammation is a stimulus for cardia intestinal metaplasia, and a reduction in inflammation may allow the metaplastic mucosa to revert to normal. The median time period between initial and repeat endoscopy in which the majority of patients showed regression of their CIM was 2.07 years. Cardia intestinal metaplasia may be a nonspecific response to cardia inflammation rather than a reaction to a specific etiologic agent $(33,34)$.

It will be interesting to observe this group of patients over a long time period in regard to identifying which subgroups of patients, if any, will develop epithelial dysplasia. Once the cardia mucosa has demonstrated the ability to produce goblet cells, is there an increased risk of epithelial dysplasia after the goblet cells have disappeared? Possibly, it is not the presence of CIM in a single endoscopy, but rather persistent CIM that puts a patient at risk for developing epithelial dysplasia. Patients with Barrett's esophagus may be at greater risk for developing dysplasia that those with transitory CIM because Barrett's esophagus is a relatively permanent metaplastic mucosa. In this vein, the future definition of patients who are at increased risk for developing adenocarcinoma of the lower esophagus may be based on the documentation of persistent intestinal metaplasia of the cardia-lower esophageal region. The controversies surrounding the endoscopic, anatomic, and histologic definitions of short segment Barrett's esophagus versus a normal cardia with goblet cell metaplasia may disappear as additional follow-up studies are performed (35). The six patients with persistent CIM in this study have been placed in Barrett's esophagus type endoscopic surveillance programs (36). The true incidence of persistent or "reappearing" CIM is unknown given the uncontrolled nature (see below), and the short follow-up period of this study. This topic requires additional study in which factors such as endoscopy technique and interval, biopsy locations, number of tissue fragments procured, and number of slides and levels evaluated are controlled.

There are several limitations to this study of which readers should be aware so that over interpretation and inappropriate conclusions are not drawn. First, it was not a controlled study. The number of biopsies procured from each patient reflects community practice standards, including differences between gastroenterologists. The detection of CIM is dependent on the number of biopsies taken. A greater number of biopsy specimens influences the detection of CIM $(5,9)$. Sampling biases, including the number of repeat endoscopies and number of biopsy tissue fragments procured from each patient in this study, undoubtedly impacted the results. Sixty-three of the 75 patients $(84 \%)$ who had no CIM on initial repeat endoscopy had no additional endoscopies, whereas four of the 12 patients (33\%) who underwent a second repeat endoscopy had CIM. This is probably the underlying cause of "reappearance" of CIM in four patients on their second repeat endoscopy, whereas it was not present in their initial repeat endoscopy. Second, this study does not address what, if any, medications the patients were on before initial endoscopy, and the type of medical therapy that was used after the initial endoscopy. Third, the reasons that the repeat endoscopies were performed were not available, for reasons identical to those in the previous point. Fourth, this study contains only a few patients with follow-up endoscopy periods of approximately 3 years, and even fewer with periods of 4 years. The long-term dysplasia risk among patients with CIM remains to be defined. Lastly, eight gastroenterologists performed the endoscopies, which probably introduced variations in definitions despite standardization discussions regarding anatomic landmarks and endoscopic descriptions. Smaller numbers of gastroenterologists would have been optimal for a controlled study. A minority of patients had different persons performing the initial and repeat endoscopies; all these patients had normal gastroesophageal junction anatomy. The gastroenterologist performing the initial and repeat endoscopies was the same individual for all the patients who had equivocal short tongues of columnar mucosa in the repeat biopsies.

This study is noteworthy because the patients were selected for their normal esophagogastric anatomy. Some authors have included short tongues of columnar mucosa in the lower esophagus as normal, and many patients have had hiatal hernias. Both of these conditions can hamper the assessment of normalcy and the distinction between a normal, but exaggerated squamocolumnar junction and short segment Barrett's esophagus (37). As pointed out by other authors, semantics and definitions can become problematic and obscure authors results $(37,38)$.

In conclusion, $93 \%$ of patients with CIM on initial endoscopy had no CIM on repeat endoscopy. An absence of CIM on repeat endoscopy was associated with decreased cardia inflammation, suggest- 
ing that the latter is the stimulus for the intestinal metaplasia.

Acknowledgments: The statistical analyses were performed by Mamtha Balasubramanian, the William Beaumont Hospital biostatistician.

\section{REFERENCES}

1. Genta RM, Huberman RM, Graham DY. The gastric cardia in Helicobacter pylori infection. Hum Pathol 1994;25:915-9.

2. Spechler SJ, Zeroogian JM, Antonioli DA, Wang HH, Goyal RK. Prevalence of metaplasia at the gastro-oesophageal junction. Lancet 1994;344:1533-6.

3. Johnston MH, Hammond AS, Laskin W, Jones M. The prevalence and clinical characteristics of short segments of specialized intestinal metaplasia in the distal esophagus in routine endoscopy. Am J Gastroenterol 1996;91:1507-11.

4. Weston AP, Krmpotich P, Makdisi WF, Cherian R, Dixon A, McGregor DH, et al. Short segment Barrett's esophagus: clinical and histological features associated endoscopic findings, and associated with gastric intestinal metaplasia. Am J Gastroenterol 1996;91:981-6.

5. Nandurkar S, Talley NJ, Martin CJ, Ng THK, Adams S. Short segment Barrett's esophagus: prevalence, diagnosis, and associations. Gut 1997;40:710-5.

6. Hackelsberger A, Gunther T, Schultze V, Labenz J, Roessner A, Malfertheiner P. Prevalence and pattern of Helicobacter pylori gastritis in the gastric cardia. Am J Gastroenterol 1997; 92:2220-4.

7. Oberg S, Peters JH, DeMeester TR, Chandrasoma P, Hagen JA, Ireland AP, et al. Inflammation and specialized intestinal metaplasia of cardiac mucosa is a manifestation of gastroesophageal reflux disease. Ann Surg 1997;226:522-32.

8. Morales TG, Sampliner RE, Bhattacharyya A. Intestinal metaplasia of the gastric cardia. Am J Gastroenterol 1997;92: $414-8$.

9. Morales TG, Bhattacharyya A, Johnson C, Sampliner RE. Is Barrett's esophagus associated with intestinal metaplasia of the gastric cardia? Am J Gastroenterol 1997;92:1818-22.

10. Trudgill NJ, Suvarna SK, Kapur KC, Riley SA. Intestinal metaplasia at the squamocolumnar junction in patients attending for diagnostic gastroscopy. Gut 1997;41:585-9.

11. Chalasani N, Wo JM, Hunter JG, Waring JP. Significance of intestinal metaplasia in different areas of the esophagus including the esophagogastric junction. Dig Dis Sci 1997;42: 603-7.

12. Goldblum JR, Vicari JJ, Falk GW, Rice TW, Peek RM, Easley K, et al. Inflammation and intestinal metaplasia of the gastric cardia: the role of gastroesophageal reflux and $H$. pylori infection. Gastroenterology 1998;114:633-9.

13. Chen Y-Y, Antonioli DA, Spechler SJ, Zeroogian JM, Goyal RK, Wang HH. Gastroesophageal reflux disease versus Helicobacter pylori infection as the cause of gastric carditis. Mod Pathol 1998;11:950-6.

14. Csendes A, Smok G, Burdiles P, Sagastume H, Rojas J, Puente G, et al. 'Carditis'. an objective histological marker for pathologic gastroesophageal reflux disease. Dis Esophagus 1998; 11:101-5.

15. Bak YT, Jung GM, Yeon JE, Kim JS, Byun KS, Kim JH, et al. Validity of the specialized columnar epithelium as a diagnostic criterion of the short segment Barrett's esophagus. Korean J Intern Med 1998;13:99-103.

16. Hackelsberger A, Gunther T, Schultze V, Manes G, Dominguez-Munoz JE, Roessner A, et al. Intestinal metaplasia at the gastroesophageal junction: Helicobacter pylori gastritis or gastroesophageal reflux disease? Gut 1998;43:17-21.
17. Byrne JP, Bhatnagar S, Hamid B, Armstrong GR, Attwood SE. Comparative study of intestinal metaplasia and mucin staining at the cardia and esophagogastric junction in 225 symptomatic patients presenting for diagnostic open-access gastroscopy. Am J Gastroenterol 1999;94:98-103.

18. Kyzekova J, Mour J. The effect of eradication therapy on histological changes in the gastric mucosa in patients with non-ulcer dyspepsia and Helicobacter pylori infection. Prospective randomized intervention study. Hepatogastroenterology 1999;46:2048-56.

19. Voutilainen M, Farkkila M, Juhola M, Mecklin JP, Sipponen P. Complete and incomplete intestinal metaplasia at the esophagogastric junction: prevalences and associations with endoscopic erosive esophagitis and gastritis. Gut 1999;45: 644-8.

20. Hirota WK, Loughney TM, Lazas DJ, Maydonovitch CL, Rholl V, Wong RKH. Specialized intestinal metaplasia, dysplasia, and cancer of the esophagus and esophagogastric junction: prevalence and clinical data. Gastroenterology 1999;1162: 277-85.

21. Pereira A, Suspiro A, Chaves P, Saraiva A, Gloria L, deAlmeida JCM, et al. Short segments of Barrett's epithelium and intestinal metaplasia in normal appearing oesophagogastric junctions: the same or two different entities? Gut 1998;42:659-62.

22. Voutilainen M, Farkkila M, Mecklin JP, Juhola M, Sipponen P. Chronic inflammation at the gastroesophageal junction (carditis) appears to be a specific finding related to Helicobacter pylori infection and gastroesophageal reflux. Am J Gastroenterol 1999;94:3175-80.

23. Nakamura M, Kawano T, Endo M, Iwai T. Intestinal metaplasia at the esophagogastric junction in Japanese patients without clinical Barrett's esophagus. Am J Gastroenterol 1999;94:3145-9.

24. de Mas C-R, Kramer M, Seifert E, Rippin G, Vieth M, Stolte M. Short Barrett: prevalence and risk factors. Scand J Gastroenterol 1999;34:1065-70.

25. Dixon A, Genta RM, Yardley JH, Correa P. Classification and grading of gastritis: the updated Sydney System. Am J Surg Pathol 1996;20:1161-81.

26. Goldstein NS, Karim R. Inflammation and intestinal metaplasia of the gastric cardia: associations with reflux esophagitis and Helicobacter pylori infection and implications for the histologic diagnosis of Barrett's esophagus. Mod Pathol 1999;12:1017-24.

27. Matsukura N, Suzuki K, Kawachi T, Aoyagi M, Sugimura T, Kitaoka $\mathrm{H}$, et al. Distribution of marker enzymes and mucin in intestinal metaplasia in human stomach and relation to complete and incomplete types of intestinal metaplasia to minute gastric carcinomas. J Natl Cancer Inst 1980;65:231-40.

28. Segura DI, Montero C. Histochemical characterization of different types of intestinal metaplasia in gastric mucosa. Cancer 1983;52:498-503.

29. Teglbjaerg PS, Nielsen HO. "Small intestinal type" and "colonic type" intestinal metaplasia of the human stomach, and their relationship to the histogenetic types of gastric adenocarcinoma. Acta Pathol Microbiol Scand 1978;86A:351-5.

30. Iida F, Murata F, Nagata T. Histochemical studies of mucosubstances in metaplastic epithelium of the stomach, with special reference to the development of intestinal metaplasia. Histochemistry 1978;56:229-37.

31. DeMeester SR, Campos GMR, DeMeester TR, Bremner CG, Hagen JA, Peters JH, et al. The impact of an antireflux procedure on intestinal metaplasia of the cardia. Ann Surg 1998; 228:547-56.

32. Sharma P, Morales TG, Sampliner RE. Short segment Barrett's esophagus-the need for standardization of the definition and of endoscopic criteria. Am J Gastroenterol 1998;93:1033-6. 
33. Sharma P, Topalovski M, Sampliner RE, Mayo M, Westin AP. $H$. pylori eradication dramatically improves inflammation in the gastric cardia (carditis) [abstract]. Gastroenterology 1999;116:A308.

34. Spechler SJ. The role of gastric carditis in metaplasia and neoplasia at the gastroesophageal junction. Gastroenterology 1999;117:218-28.

35. Spechler SJ, Goyal RK. The columnar-lined esophagus, intestinal metaplasia, and Norman Barrett. Gastroenterology 1996;110:614-21.
36. Salo JA, Salminen JT, Kiviluoto TA, Nemlander AT, Ramo OJ, Farkkila MA, et al. Treatment of Barrett's esophagus by endoscopic laser ablation and antireflux surgery. Ann Surg 1998;227:40-4.

37. Sharma P, Sampliner RE. Short segment Barrett's esophagus and intestinal metaplasia of the cardia-it's not all symantics!!! Am J Gastroenterol 1998;93:2303-4.

38. Nandurkar S, Talley NJ. Barrett's esophagus: the long and the short of it. Am J Gastroenterol 1999;94:30-40.

\section{Book Review}

\section{Kanel GC, Korula J: Liver Biopsy Evaluation- Histologic Diagnosis and Clinical Correla- tions, 255 pp, Philadelphia, W.B. Saunders, 2000 (\$139).}

There are several pathology texts that describe the histologic features of the diseases that affect the liver. These require that one already knows the disease entity. The construction of Drs. Kanel and Korula's book is more in keeping with how a surgical pathologist evaluates a liver biopsyafter recognizing the different histology findings, he or she would need to decide what the possible causes are.

The book is divided into five chapters. Chapter 1 is a short "Introduction" that reviews the principles of liver biopsy assessment and also explains the construction and use of the book. Chapter 2 is titled "Morphological Landmarks in Liver pathology." The authors have selected 35 histologic findings, arranged alphabetically, starting with "Abscess Formation" and ending with "Vessels (excluding sinusoids). Thrombosis and Occlusion." Under each finding there is a brief discussion, a table listing the possible associated diseases, and selected illustrations of the more common diseases. Chapter 3 is titled "Liver Diseases: Pathology and Clinical Considerations." In this section, the diseases (230 in all) are listed alphabetically and the major histologic and clinical/laboratory parameters are listed in table format. Several references also are provided for each disease entity. In Chapter 4, "DrugInduced and Toxic Liver Cell Injury," the authors have selected 20 different types of liver injury under which are listed the various associated drugs and toxins. Finally, there are more than 1000 references listed in Chapter 5.

This is not the first book organized by histologic findings. However, the strengths and uniqueness of this book are the inclusion of 230 different diseases with a listing of both major histologic findings as well as clinical/laboratory parameters, the good to excellent illustrations, and the alphabetical organization, which greatly facilitates the use of the book. Finally, a comprehensive and more up-to-date listing of drugs/ toxins that cause liver disease is always useful.

This is probably not the book that one would use to start to learn about liver pathology. However, if one has a basic foundation, I think having a book organized in this way is invaluable.

\author{
Kathryn E. Tanaka \\ Montefiore Medical Center/Albert Einstein \\ College of Medicine \\ Bronx, New York
}

